\title{
THE ETRUSCANS IN 3D: FROM SPACE TO UNDERGROUND
}

\section{Fabio REMONDINO ${ }^{1}$, Alessandro RIZZI ${ }^{1}$, Belen JIMENEZ ${ }^{1}$, Giorgio AGUGIARO ${ }^{1}$, Giorgio BARATTI ${ }^{1,3}$, Raffaele DE AMICIS ${ }^{2}$}

\author{
${ }^{1}$ 3D Optical Metrology Unit, Bruno Kessler Foundation (FBK), Trento, Italy \\ E-mail: $\{$ remondino, rizziale, bjfernandez, agugiaro, baratti $\} @$ fbk.eu \\ Web: http://3dom.fbk.eu \\ ${ }^{2}$ Fondazione Graphitech, Trento, Italy \\ E-mail: raffaele.de.amicis@graphitech.it - Web: http://www.graphitech.it \\ ${ }^{3}$ Dip. Scienze dell'Antichità - University of Milano, Italy \\ E-mail: giorgio.baratti@unimi.it
}

Keywords: Photogrammetry, Laser scanning, Geo-browser, Panoramic images, 3D modeling,, Visualisation

\begin{abstract}
Geomatics and Geoinformatics deal with spatial and geographic information, 3D surveying and modeling as well as information science infrastructures. Geomatics and Geoinformatics are thus involved in cartography, mapping, photogrammetry, remote sensing, laser scanning, Geographic Information Systems (GIS), Global Navigation Satellite Systems (GNSS), geo-visualisation, geospatial data analysis and Cultural Heritage documentation. In particular the Cultural Heritage field can largely benefit from different Information and Communication Technologies (ICT) tools to make digital heritage information more informative for documentation and conservation issues, archaeological analyses or virtual museums. This work presents the 3D surveying and modeling of different Etruscan heritage sites with their underground frescoed tombs dating back to VII-IV century B.C.. The recorded and processed 3D data are used, beside digital conservation, preservation, transmission to future generations and studies purposes, to create digital contents for virtual visits, museum exhibitions, better access and communication of the heritage information, etc.
\end{abstract}
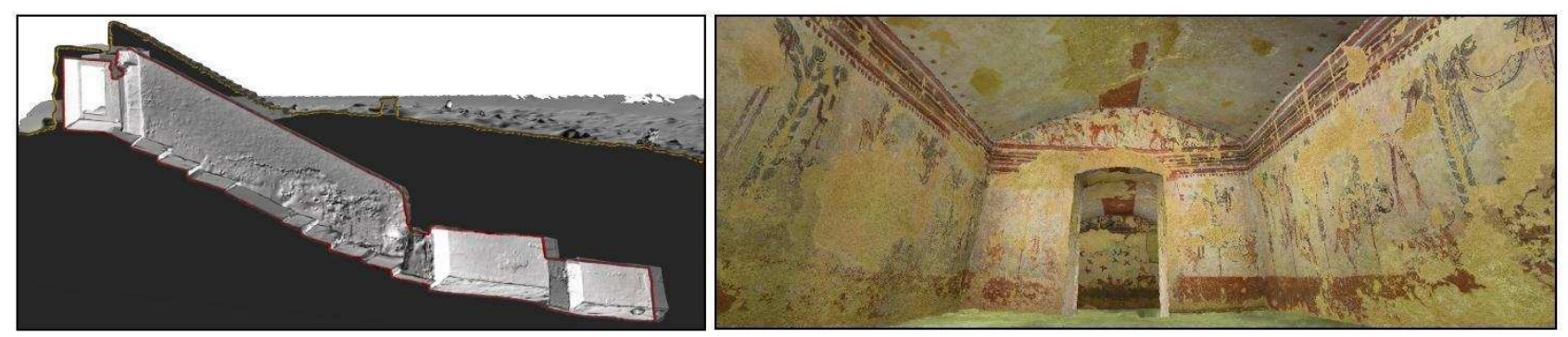

Figure 1: 3D surveying and modeling of a frescoed underground Etruscan tomb (Hunting and Fishing, necropolis of Tarquinia, Italy) for archaeological documentation, virtual access, digital preservation and architectural analyses.

\section{INTRODUCTION}

Art and history are essential and recognizing elements for a country (or a civilization) - be it a present or a past one since they play a crucial role in a community's culture and education: heritages must be therefore preserved and made available to the future generations. At the same time, Cultural Heritages represent an important asset for tourism and it is reasonable to make them (digitally) available to a larger number of people, especially if they can be visited/accessed in a way that preserves them causing no further damages. Nowadays disciplines dealing with Geomatics and Geoinformatics offer (i) great potentialities for the accurate and detailed 3D documentation and digital preservation of existing tangible heritages [1-3] and (ii) a large number of tools to make digital heritages more informative, easier to be visited and enjoyed even remotely. Indeed, beside digital documentation and conservation material (Figure 1), virtual 
museums, virtual-environment caves and multimedia exhibitions - just to name some - are becoming everyday more common, because they allow for interaction, on-demand information retrieval, integration of artefacts in their original context, virtual tours, immersive experiences for inaccessible sites, time-based 4D navigation, e-education, etc. In many cases, the number of on-line visitors of "virtual museum" has already outnumbered the on-site physical visitors, clearly showing a slow but continuous shift in the perception of how museum contents are "consumed". Digital contents are thus being progressively accepted and enjoyed besides the "classical" physical artifacts. With these points in mind, this paper presents and discusses experiences and results collected by the authors in the framework of 3D surveying and modeling of some Etruscan heritage sites in the centre of Italy: the two necropolises in Tarquinia and Cerveteri (UNESCO World Heritage site since 2004) and the necropolis in Chiusi. They all feature hypogenous tombs dating back to the VII-IV century B.C.. Some tombs are single-roomed, other present a more articulated architectonical structure, with different chambers mostly full of frescoed walls and ceilings. The work followed some fundamental steps in order to satisfy the project requirements (Figure 2). 3D data were acquired during three distinct campaigns in 2009, 2010 and 2011, using different techniques that range from terrestrial laser scanning to high-resolution panoramic and multi-spectral imaging. All acquired data were successively used and integrated with other existing sources (e.g. satellite imagery, DTM, tabular data, etc.) to produce heterogeneous, multi-scale digital contents conceived for digital heritage preservation, archaeological and architectural analyses, virtual museums, multimedia exhibitions and webapplications. Reality-based 3D models, monoscopic and anaglyph visualizations, interactive virtual tours, a geo-browser platform and some documentary materials were created. They guarantee an accurate and digital documentation as well as access to otherwise hardly reachable underground tombs and locations, which may be often closed to the public for preservation reasons. The produced 3D models were also used for analyses and investigations on the tomb geometries, to validate archaeological hypotheses or to make new ones.
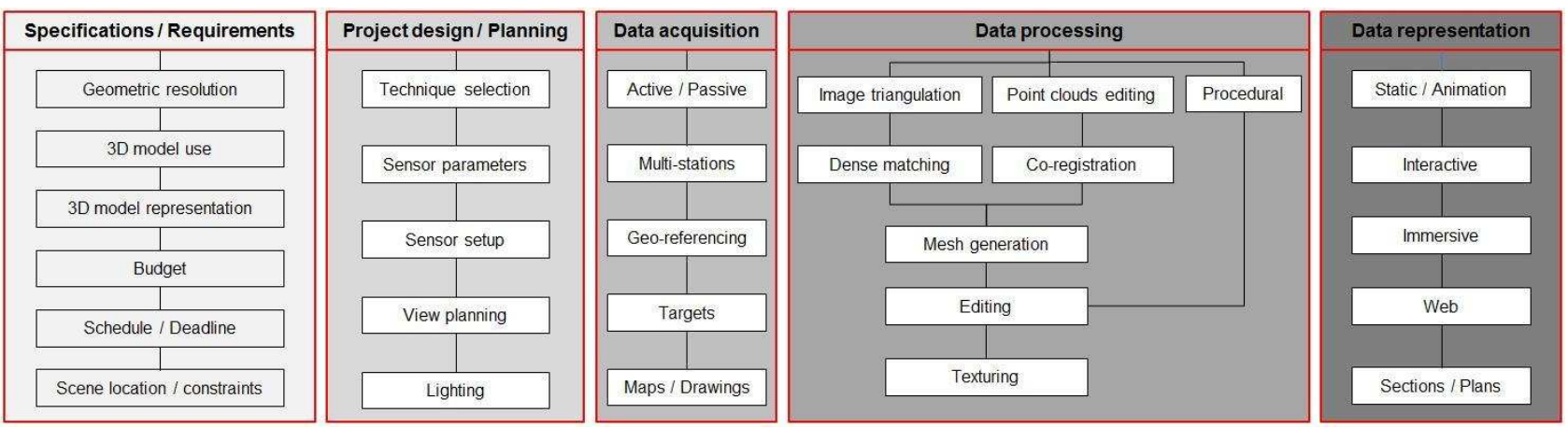

Figure 2: The different steps in 3D surveying and modeling projects dealing with large sites or complex architectures: specifications, planning, acquisitions, processing and final representation.

\section{SURVEYING AND 3D MODELLING}

\subsection{Data acquisition}

\subsubsection{Panoramic and multi-spectral imaging}

Digital images acquired in the visible, IR and UV domains are used for 3D reconstructions (photogrammetry), virtual visits of the sites and diagnostics studies. The documentation with spherical or panoramic photography is becoming a very common practice for many kinds of visual applications (e.g. Google Street View, 1001 Wonders, etc.). In addition, the derivation of metric results from spherical images for interactive exploration, accurate documentation and realistic $3 \mathrm{D}$ modeling is receiving great attention due to high-resolution content, large field-of-view, low-cost, easiness, rapidity and completeness of the method [4]. Panoramic images are generally acquired with dedicated rotating linear sensors or, more economically, stitching together multiple frame images acquired rotating the camera around the perspective centre. Multi-spectral imaging (e.g. visible reflectance, IR reflectography and UV-induced fluorescence) provides very useful information about the employed painting materials, allowing analyses of frescoed areas. Multi-spectral images, acquired with a cooled CCD camera coupled with interferential filters, need to be radiometrically calibrated, registered, processed and finally overlapped onto the 3D geometry in order to perform quantitative analyses and differentiate colors and pigments. The latter may be present, hidden or invisible to the naked eye. But materials showing the same color in a certain part of the light spectrum can have different chemical compositions and reflectance spectra and thus can be identified with multi-spectral imaging [5]. 


\subsubsection{Range data}

Optical active sensors [6], generally Time-of-Flight (TOF) and triangulation-based range instruments can easily provide dense and accurate 3D point clouds at very high geometric resolution. In case of large and complex sites, TOF sensors are an excellent and powerful solution to collect 3D data (Figure 3) and create accurate surface models. Generally, the instrument has to be located in different positions and afterwards the recorded unstructured point clouds need to be coregistered in a unique reference system.
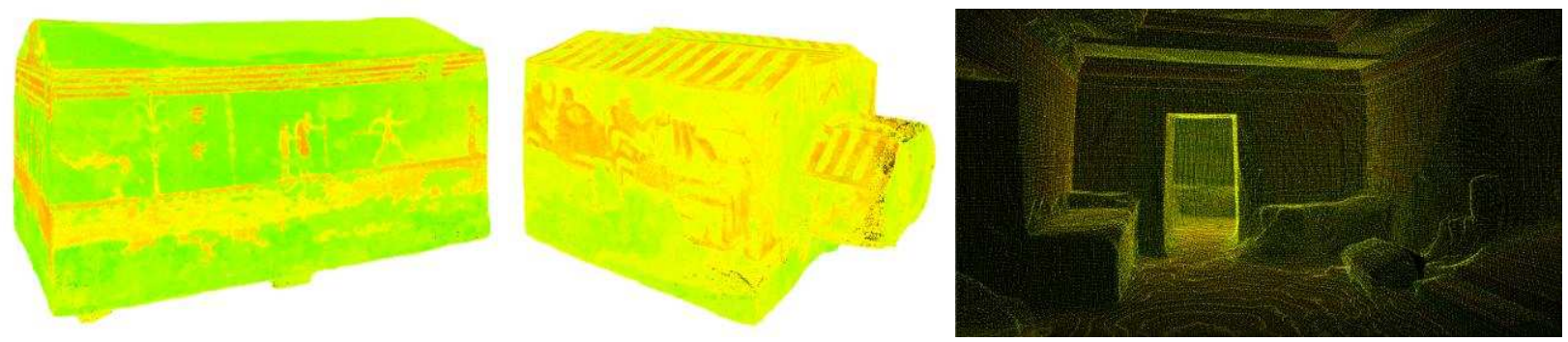

Figure 3: Typical range-based point clouds acquired with a TOF laser scanner, visualized in color-code mode.

\subsection{D modelling}

The acquired range-based point clouds must be converted into structured polygonal models to digitally recreate the geometric shapes of the surveyed objects and allow better photo-realistic visualization. A geometric polygonal model offers much more possibilities than a simple rendering of the point cloud. HDR images, acquired with separate cameras, are mapped onto the reconstructed 3D geometry for photo-realistic visualization, restoration, conservation purposes and ortho-image generation. If multi-spectral images are also mapped onto the $3 \mathrm{D}$ geometry, they turn into quantitative information for metric and diagnostic purposes.

\section{DATA VISUALISATION AND ACCESS}

\subsection{D Geo-browser}

The contextualization of an entire civilization or large heritage sites can be achieved with modern geographic browsers (e.g. Google Earth or NASA World Wind) or web-based 3D tools [7-9]. Existing 3D-GIS databases can be of great value to build up virtual environments with a friendly and flexible user interface, customizing the databases with dedicated cultural information (Figure 4). Textual information, images, video and 3D models can be added and visualized on-demand together with the 3D geographic information. The user can easily fly over the landscape, activate different layers of data and read archaeological information.
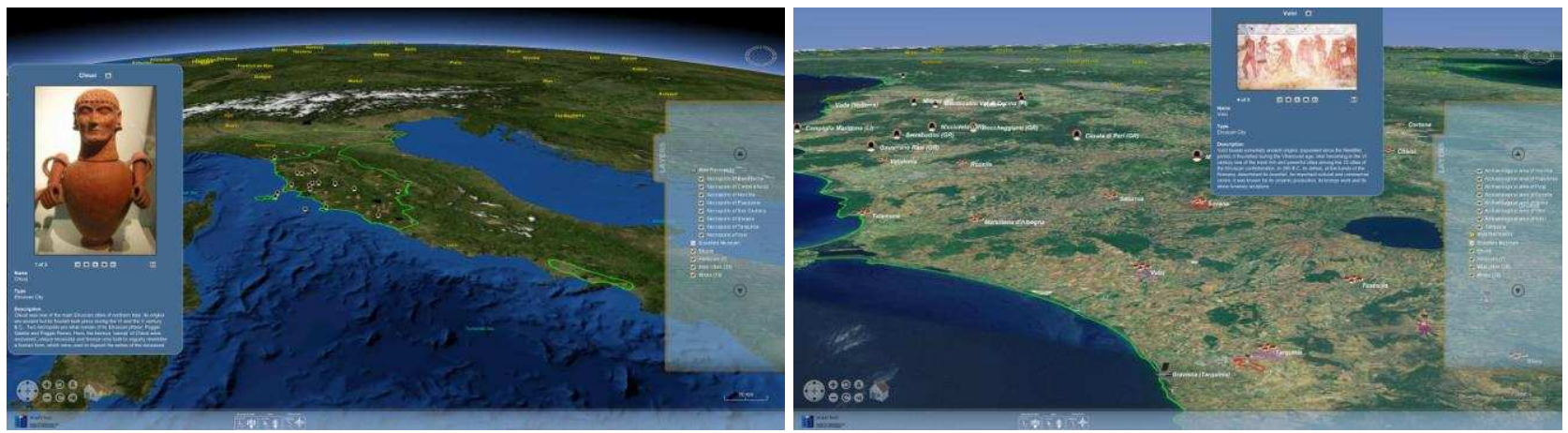

Figure 4: Examples of the customized geo-browser which allow the visualization of information related to the Etruscan civilization, its extents in Italy, archaeological areas, harbors and mines, necropolises, etc.

\subsection{Image-based rendering}

High-resolution panoramic images of a necropolis can be linked together to create virtual tours, which are enriched by means of architectural and archaeological information regarding the site, the civilization and the single monuments 
(Figure 5). Such application thus allows a user to virtually navigate through the site, obtain information on-demand (text, images, video, stereoscopic views, etc.) and access areas generally closed to the public for conservation reasons.
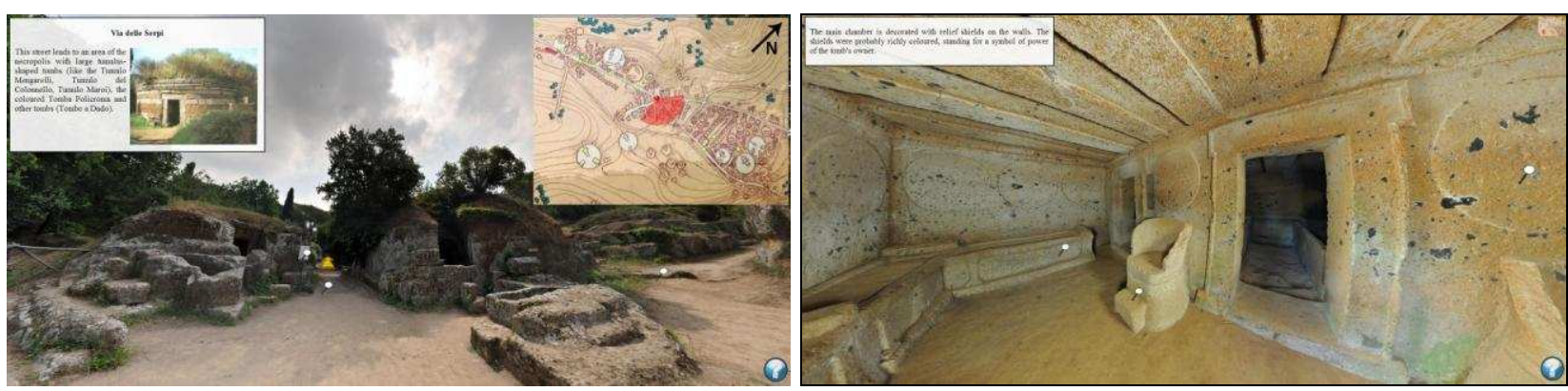

Figure 5: Examples from the virtual tour of the Banditaccia necropolis in Cerveteri. Multiple high-resolution panoramas are linked together and navigable allowing an immersive tour of the heritage site, in particular for those areas closed to the public for conservation reasons. Additional information (text, images, video, etc.) is provided by means of linkable hotspots.

\subsection{Monoscopic and stereoscopic visualisation}

The produced 3D models (Figure 6) are rendered using predefined flying paths in monoscopic and stereoscopic (anaglyph) videos. Indeed the interactive visualization of large geometric (more than 10 million polygons) and textured 3D models is still problematic and an open issue for the research community. Therefore offline presentations and renderings are currently the most exploitable solutions for non-experts and museum exhibitions.
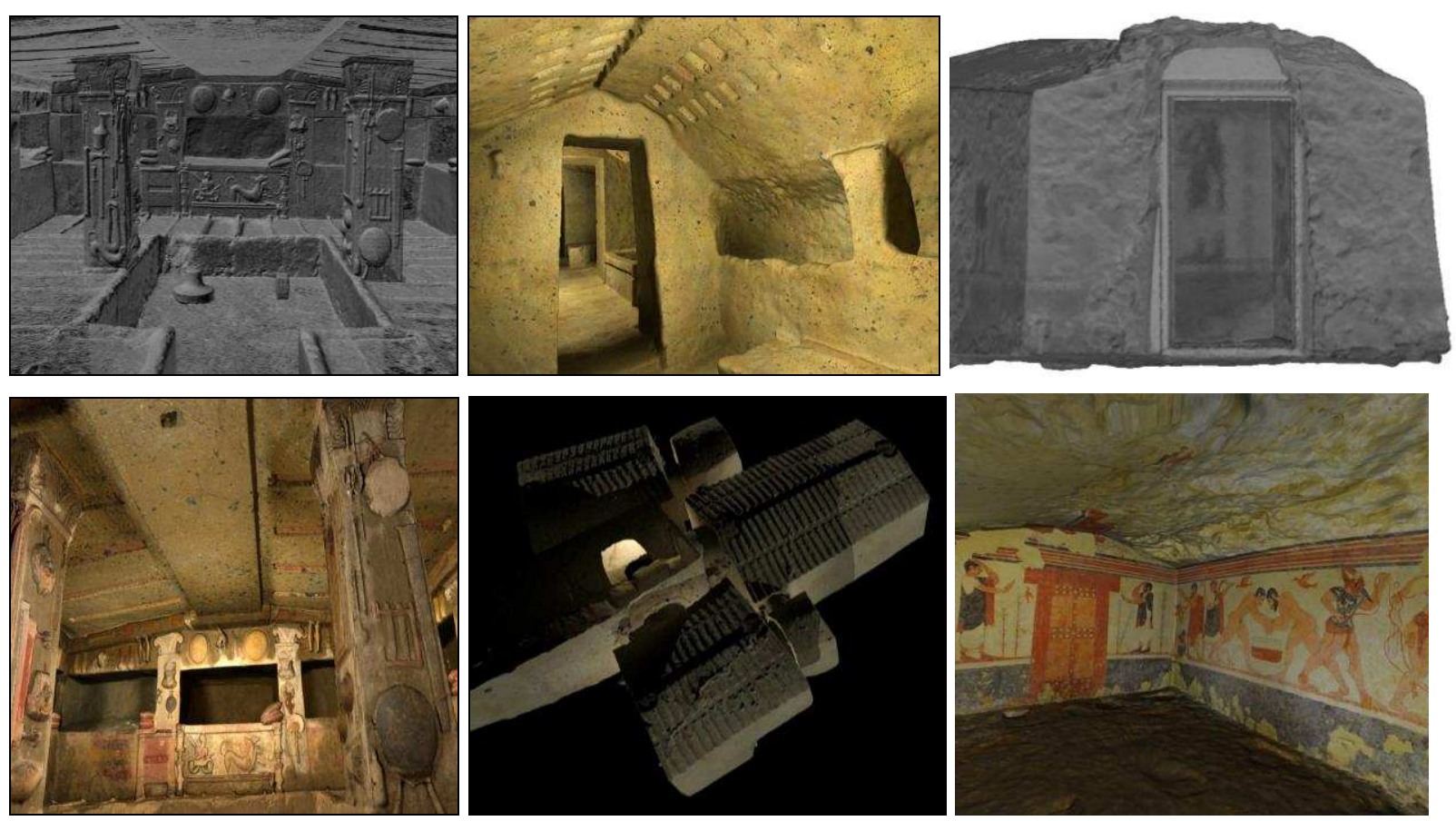

Figure 6: Some views of the created 3D models rendered in shaded or textured mode for monoscopic or stereoscopic visualization. Left: Tomb of the Reliefs (IV cent. B.C., necropolis of Cerveteri). Centre: Tomb of the Painted Lions (VII cent. B.C., necropolis of Cerveteri). Right: Tomb of the Augurs (VI cent. B.C., necropolis of Tarquinia).

\section{ARCHAEOLOGICAL AND ARCHITECTURAL ANALYSES}

Heritage 3D models can be used not only for digital documentation, conservation, visualization and data exploration purposes, but also to perform deep analyses on the geometric structures and constructive methods. In the case of a wall, 
for example, it is possible to analyze its shape and inclination, evaluating the orthogonality with respect to other walls or its perpendicularity with respect to the floor. There are many useful software tools that allow to investigate the geometry of a 3D model, but they are of little help if the geometric quality of the model is inadequate. For this reason, it is very important to use reality-based 3D data representing the surveyed scene as accurately as possible. The 3D model's resolution is an important parameter to consider [10] because it is related to the level of detail (LoD) the model is conceived for, therefore it is an intrinsic quality parameter regarding the goodness of measurements that can be taken on it: the coarser the resolution, the less reliable and exact the measurements will tend to be.

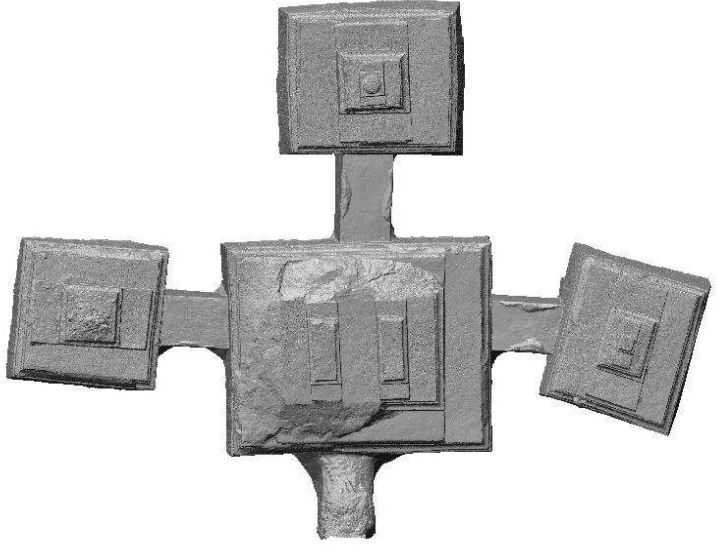

(a)

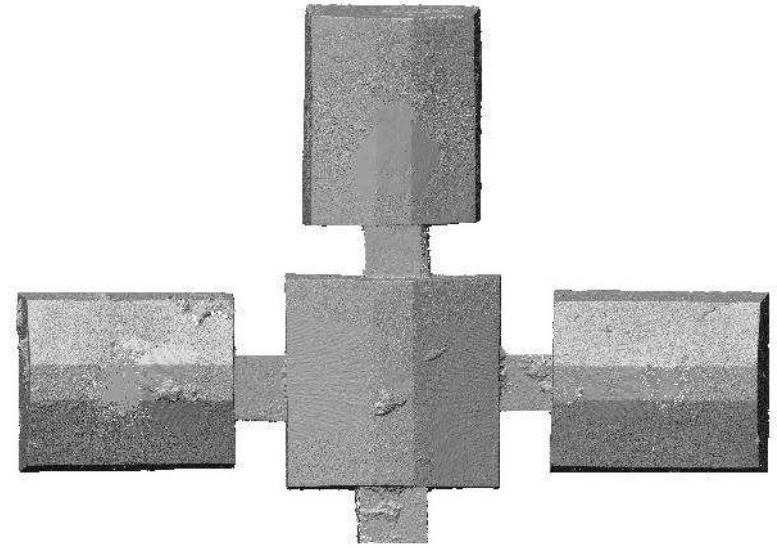

(b)

Figure 7: Geometric 3D models of (a) the Tomb of the Monkey (16 million triangles) and (b) the Bartoccini Tomb (15 million triangles).

Figure 7 presents the Tomb of the Monkey (necropolis of Chiusi, V cent. B.C.) and the Bartoccini Tomb (necropolis of Tarquinia, VI cent. B.C.), chosen because of their multiple frescoed chambers with irregular geometries. For archaeological and architectural analyses, longitudinal and transversal sections are particularly interesting for such complex monuments. Using a detailed 3D model, it is indeed possible to visualize both the internal and external parts of the tombs more conveniently and accurately, analyze every single structure and the internal geometries, showing the burial beds, the shapes and profiles of the roofs and allowing the derivation of structure measurements (Figure 8).

a)

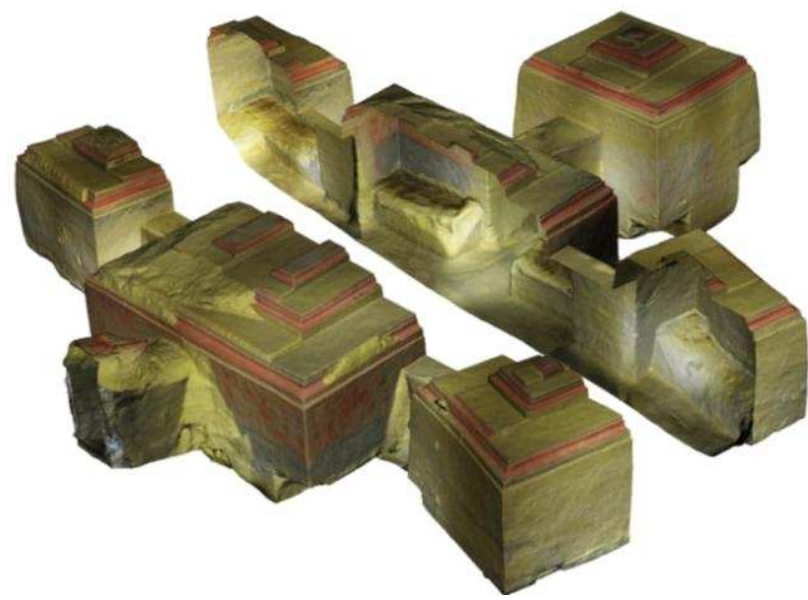

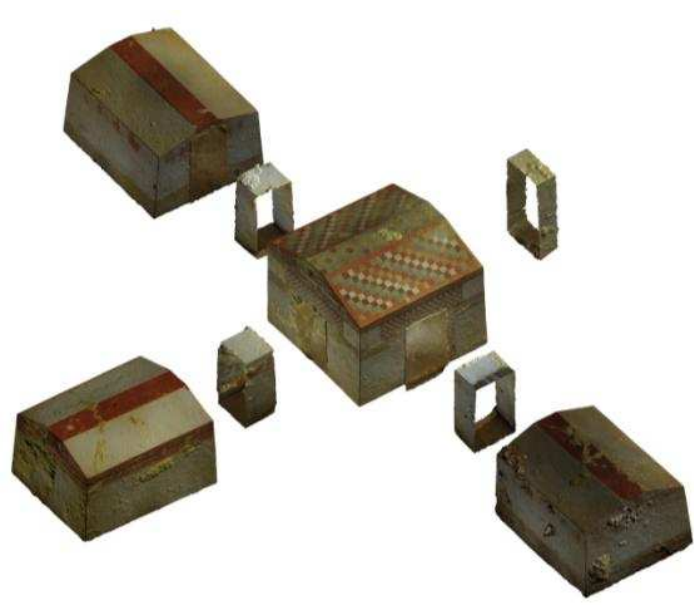

b)

Figure 8: Perspective views of the split and exploded textured 3D models of the Tomb of the Monkey (a) and the Bartoccini Tomb (b).

An orthogonal view of the Tomb of the Monkey (Figure 9a) clearly shows that the tomb is not symmetric and the position of each room is unrelated if compared to the other rooms. An old archaeological survey [11] shows, on the contrary, a more regular geometry of the tomb, with more symmetric side rooms (Figure 9b). Thus, modern 3D recording and modeling methodologies, coupled with architectural analyses realized with dedicated procedures [12], 
allow a more precise and correct surveying and structure representation. Similar geometric surveying and analyses lead to interesting results and new hypotheses in archaeology $[13,14]$.

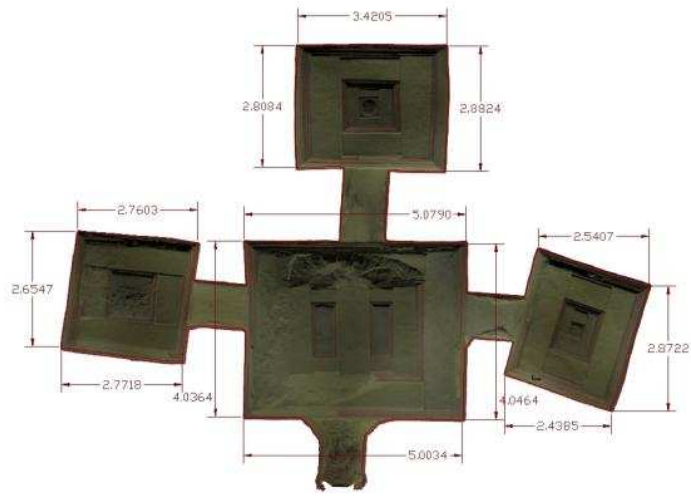

(a)

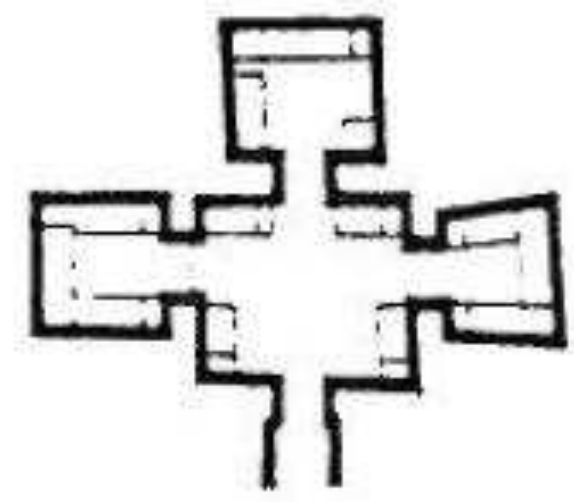

(b)

Figure 9: Tomb of the Monkey: comparison between the new produced map (a) and the old one (b).

Further architectural and geometrical studies were conducted on the inner walls and on their geometric flatness, by comparing each wall with its fitting plane. Results, shown in Figures 10(a)(c), show for each inner wall a different variation in geometry and no similar value can be found, probably due to structure deteriorations caused by the passing of time. Other analyses considered the orthogonality of the inner walls of the rooms with respect to the ground floor. Results in Figures 10(b)(d) underline that each inner wall has practically the same inclination value and that the inclination is oriented toward the inside of the room. This is coherent with the hypotheses of the archaeologists: Etruscan tombs were built in a similar way of Etruscan houses.

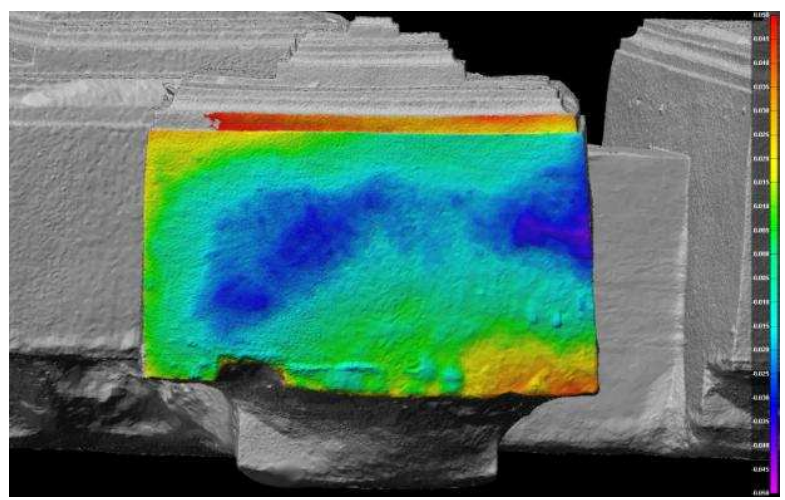

(a)

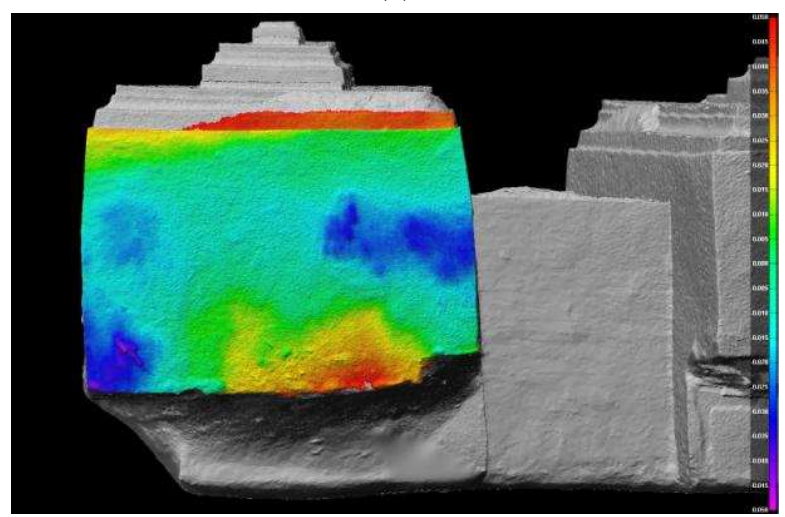

(c)

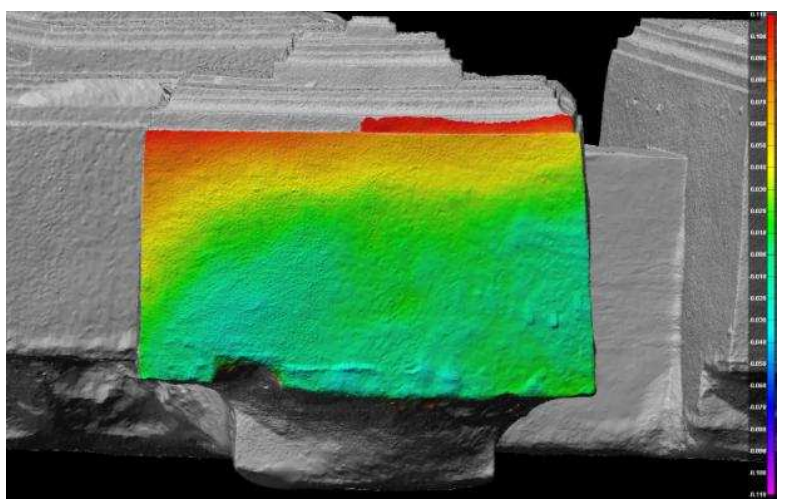

(b)

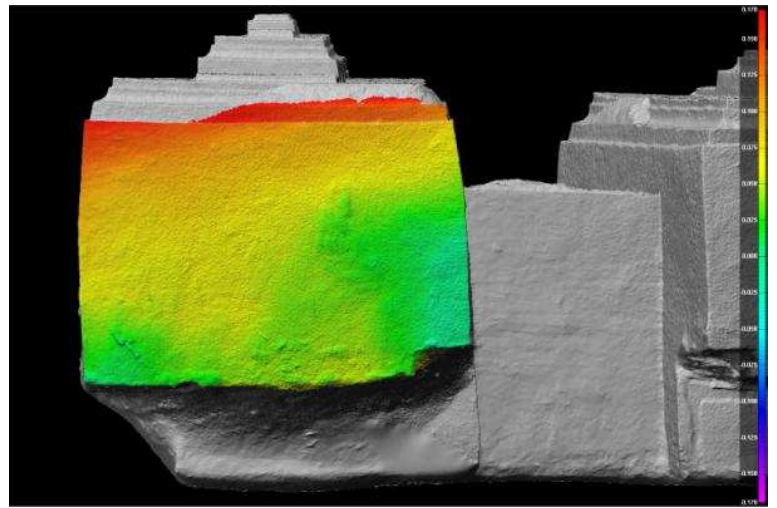

(d)

Figure 10: Geometric analyses on two side rooms of the Tomb of the Monkey. On the left column (a, c), difference maps between inner walls geometries and their fitting planes. On the right column (b, d), difference maps between inner walls geometries and a vertical plane. 
Thanks to reality-based 3D models it is moreover possible to derive precise metric measures, not only in linear terms as distances from point to point, but also areas and volumes. Thus, it is possible to catalogue each tomb with more accuracy and, for example, evaluate how many cubic meters the Etruscans extracted during the realization of a tomb. Moreover, precise size measurements of rooms, passages, entrances and of other features (e.g. funeral beds) might contribute to derive new hypotheses about the physical characteristics of the Etruscan man or regarding the construction techniques. Such values were derived for every room of the surveyed tombs. Comparisons of these data with analogous ones of other tombs built in different epochs and locations can be now performed, in order to search for similarities or new connections in the Etruscan world. For example, the Tomb of the Monkey features very similar volumes of the lateral rooms $\left(17,3 \mathrm{~m}^{3}\right.$ left room, $17,5 \mathrm{~m}^{3}$ right room), while the frontal room is bigger $\left(24 \mathrm{~m}^{3}\right)$. This difference is not visible during a real-life exploration of the tomb (which is generally forbidden to the public). The main central room spans approximately $47 \mathrm{~m}^{3}$, while the global volume of the entire tomb yields $123 \mathrm{~m}^{3}$. Since part of the main room's ceiling in the Tomb of the Monkey collapsed in the past, a virtual model of the reconstructed ceiling could be created starting from the existing surveyed structures. Comparative views are given in Figure 11 showing not only the geometries, but also the frescoes. The virtual reconstruction analysis allowed to measure the volume of the collapsed part $\left(0,8 \mathrm{~m}^{3}\right)$, too. Further studies on the ceiling shapes can also be performed, as shown also in [13, 14].

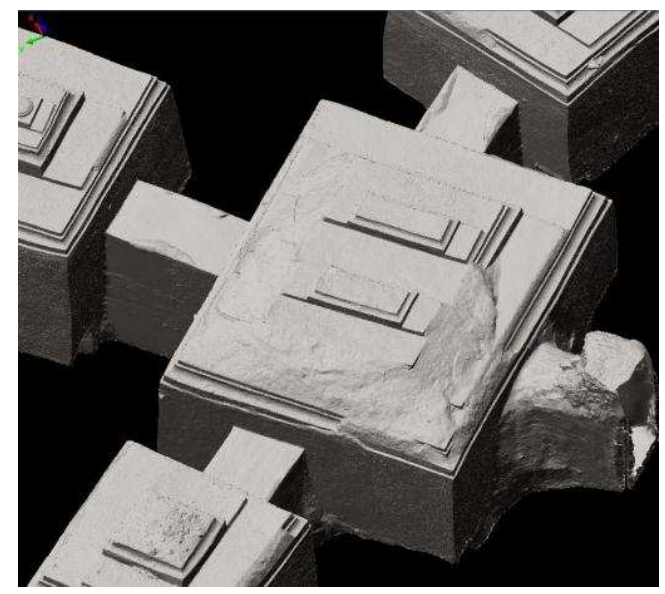

(a)

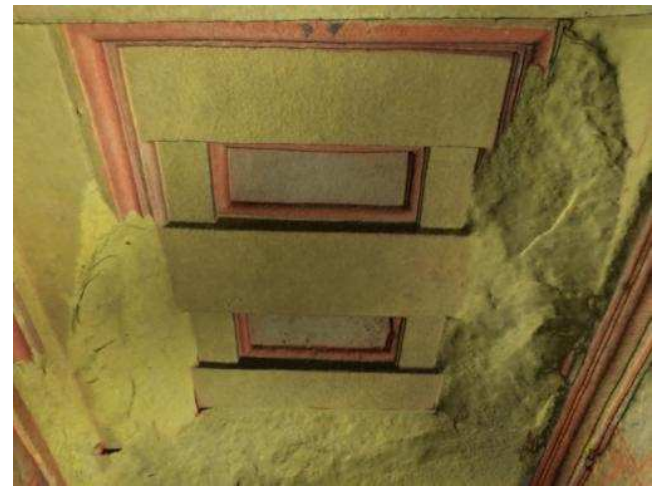

(c)

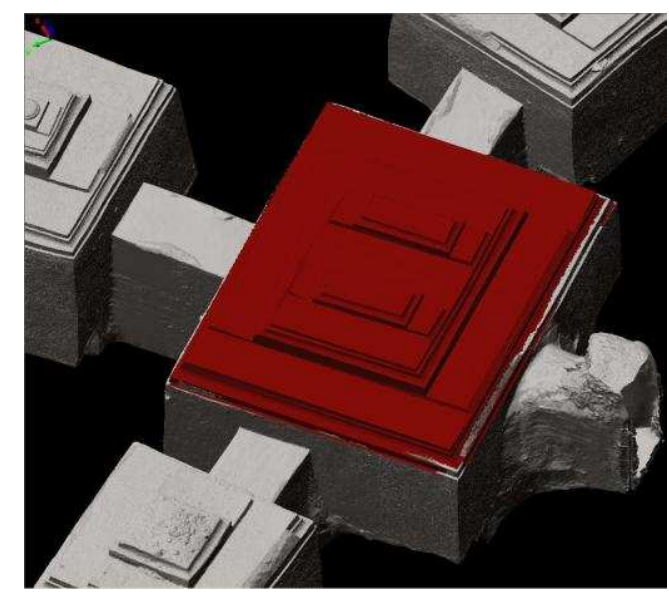

(b)

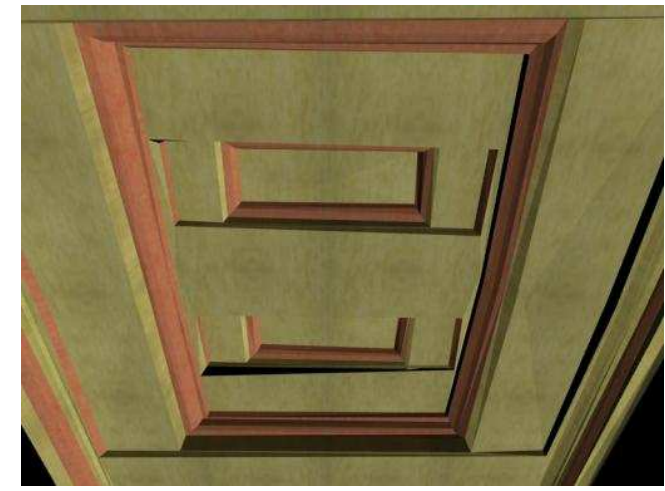

(d)

Figure 11: The collapsed ceiling in the Tomb of the Monkey, shown from outside (a) and inside (b) the surveyed and modeled tomb; the virtual geometric reconstruction of the ceiling seen from outside (b) and inside (d).

\section{CONCLUSIONS}

Geomatics and Geoinformatics are showing great potentialities for a better documentation, communication, understanding and preservation of Cultural Heritage. Innovative applications in the heritage field are therefore available, also for the future of museums and exhibitions. Digital contents and advanced tools for remote and interactive data access and visualization, immersive experience, virtual visits and e-education are the basis to increase the communication and study of heritage, to ease the retrieval of visual information and to digitally transmit culture to the 
future generations. As shown in the article, archaeological researchers can have great benefits from reality-based 3D data for their studies. In particular they can deeply investigate many archaeological masterpieces from different points of view and calculate with high accuracy their geometries. Thanks to these new methodologies, it might be possible to validate previously existing theories or formulate new ones related e.g. to construction methods. What is expected for the near future is an emerging practice of representing and communicating heritage information through new ICT tools, not only with standard documentation material, but also via web applications or in museums and exhibitions.

\section{ACKNOWLEDGMENTS}

The authors are really thankful to the Soprintendenza per i Beni Archeologici dell'Etruria Meridionale (Dr A.M. Moretti, Dr R. Cosentino, Dr M. Cataldi), Soprintendenza per i Beni Archeologici della Toscana (Dr M. Salvini), Historia (http://www.historiaweb.it) and Art-Test (http://www.art-test.com), partners and supporters for the reported work.

\section{REFERENCES}

[1] Ikeuchi, K., Miyazaki, D. (Eds): Digitally archiving Cultural Heritage, Springer, 503 pages, 2007.

[2] Patias, P.: Cultural heritage documentation. In: Fryer J, Mitchell H, Chandler J (Eds), Application of 3D measurement from images, Chapter 9, Whittles, Dunbeath, 2007.

[3] Remondino, F., Rizzi, A.: Reality-based 3D documentation of natural and cultural heritage sites - Techniques, problems and examples. Applied Geomatics, Vol.2(3): 85-100, 2010.

[4] Barazzetti, L., Fangi, G., Remondino, F., Scaioni, M.: Automation in multi-image spherical photogrammetry for 3D architectural reconstructions, Proc. of 11th Int. Symposium on Virtual Reality, Archaeology and Cultural Heritage (VAST 2010), Paris, France, 2010.

[5] Remondino, F. Rizzi, A., Barazzetti, L., Scaioni, M., Fassi, F., Brumana, R., Pelagotti, A.: Geometric and Radiometric Analyses of Paintings. The Photogrammetric Record, in press, 2011.

[6] Vosselman, G., Maas. H-G. (Eds): Airborne and terrestrial laser scanning. CRC, Boca Raton, 318 pp. ISBN: $978-$ 1904445-87-6, 2010.

[7] Conti, G., Simões, B., Piffer, S., De Amicis, R.: Interactive processing service orchestration of environmental information within a 3D web client. Proc. GSDI 11th World Conference on Spatial Data Infrastructure Convergence, Rotterdam, The Netherlands, 2009.

[8] Manferdini, A., Remondino, F.: Reality-based 3D modeling, segmentation and web-based visualisation. Proc. of EUROMED 2010, LNCS 6436, Springer Verlag, pp. 110-124, 2010.

[9] Agugiaro, G., Remondino, F., Girardi, G., Von Schwerin, J., Richards-Rissetto, H., De Amicis, R., 2011: A webbased interactive tool for multi-resolution 3D models of a Maya archaeological site. Int. Archives of Photogrammetry, Remote Sensing and Spatial Information Sciences, Vol. 38(5/W16), on CD-ROM. 4th Int. Workshop "3D-ARCH 2011: "Virtual Reconstruction and Visualization of Complex Architectures", 2-5 March 2011, Trento, Italy.

[10] Guidi, G., Remondino, F., Russo, M., Menna, F., Rizzi, A., Ercoli, S.: A multi-resolution methodology for the 3D modeling of large and complex archaeological areas. International Journal of Architectural Computing, Vol. 7(1), pp. 39-55.

[11] Steingraeber, S. (ed): Catalogo ragionato della pittura Etrusca, Jaca Book, ISBN 88-16-60046-2, 1985.

[12] Rizzi, A., Baratti, G., Jimenez, B., Girardi, S., Remondino, F.: 3D recording for 2D delivering - The employment of 3D models for studies and analyses. Int. Archives of Photogrammetry, Remote Sensing and Spatial Information Sciences, Vol. 38(5/W16), on CD-ROM. 4th Int. Workshop "3D-ARCH 2011: "Virtual Reconstruction and Visualization of Complex Architectures", 2-5 March 2011, Trento, Italy.

[13] Blersch. D, Balzani M., Tampone G.: The simulated timber structure of the Volumnis' hypogeum in Perugia, Italy, Proc. of 5th Int. Conference on Structural Analysis of Historical Constructions: Possibilities of Numerical and Experimental Techniques, Vol.1, pp. 327-334, New Delhi, India, 2006.

[14] Blersch. D, Balzani M., Tampone G., The Volumnis' hypogeum in Perugia, Italy. Application of 3D survey and modeling in archaeological sites for the analysis of deviances and deformations. Proc. 2nd Int. Conference on Remote Sensing in Archaeology "From Space to Place", pp. 389-394. 